\title{
Congenital scalp defects with distal limb anomalies Report of a family
}

\author{
BARBARA K. BURTON, LYNN HAUSER, and HENRY L. NADLER \\ From the Division of Genetics, Children's Memorial Hospital and Department of Pediatrics, Northwestern University, \\ Chicago, Illinois, USA
}

Summary. A family is reported in which the syndrome of congenital scalp defect with distal limb anomalies is expressed in several members. This provides additional evidence for the autosomal dominant inheritance of this disorder.

The occurrence of isolated congenital scalp defects has been described repeatedly (Feud et al, 1945; Callaway et al, 1946; Beresford and Samman, 1948; Walker et al, 1960; Hodgman et al, 1965; Johnsonbaugh et al, 1965; Cutlip et al, 1967). Many of the reported cases have been familial and others have been associated with a variety of chromosomal abnormalities. There have been 4 case reports describing congenital scalp defects in association with distal limb anomalies (Adams and Oliver, 1945; Scribanu and Temtamy, 1975), suggesting that this may be a distinct genetic entity. Pedigrees in 2 of these reports are indicative of autosomal dominant inheritance (Adams and Oliver, 1945; Kahn and Olmedo, 1950; Farmer and Maxmen, 1960; Scribanu and Temtamy, 1975). One other report describes an affected individual with normal parents but a sib with a scalp defect, suggesting the possibility of autosomal recessive inheritance (Kahn and Olmedo, 1950). The fourth report includes 2 unrelated individuals with no other affected family members (Farmer and Maxmen, 1960). In the latter 2 reports, no definite association is made between the scalp defects and the limb anomalies.

We report here an additional family in which the combination of congenital scalp defects and distal limb anomalies appears to be inherited as an autosomal dominant disorder (Fig. 1).

\section{Case report}

The proband (III.5), a 2-week-old Spanish-American female, was the full-term product of an uncomplicated

Received 18 September 1975. pregnancy, labour, and vertex delivery to a 32-year-old gravida 5, para 4 mother. The birthweight was $2663 \mathrm{~g}$ and the child did well in the immediate postnatal period. She was discharged from the nursery at $\mathbf{4}$ days of age.

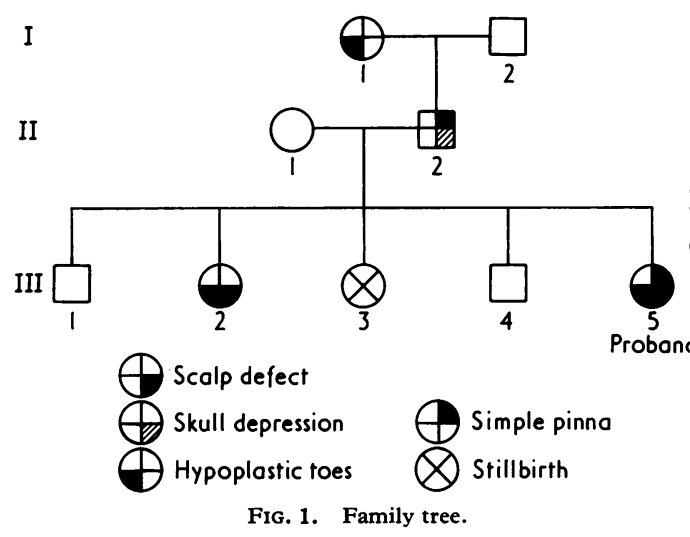

The infant presented to the emergency room of Children's Memorial Hospital at 14 days of age with a 4-day history of vomiting and diarrhoea. She was admitted to the hospital and treated for gastroenteritis, with a good clinical response. Physical examination during the child's period in hospital showed a length and weight between the 3rd and 10th centiles for age, and a head circumference at the 25 th centile for age. Generalized cutis marmorata was noted. A $1 \times 2 \mathrm{~cm}$ smooth defect, with a crusted central portion, was present at the vertex of the scalp extending forward in the midline (Fig. 2). There was no palpable skull defect and $x$-ray films confirmed the absence of a bony defect. The right ear was noted to have a simple pinna while the left ear appeared normal. The toes of both feet were hypoplastic (Fig. 3a) and $x$-ray films showed absence of the distal phalanges in all except the right great toe (Fig. 3b). 


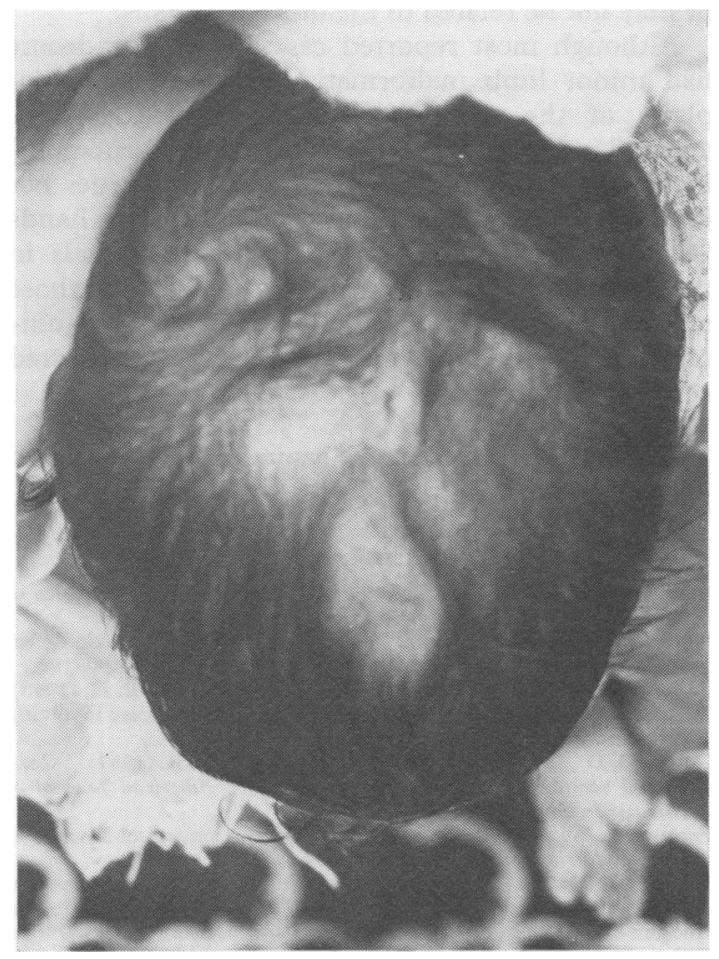

Fig. 2. Photograph of proband's head showing the congenital scalp defect.

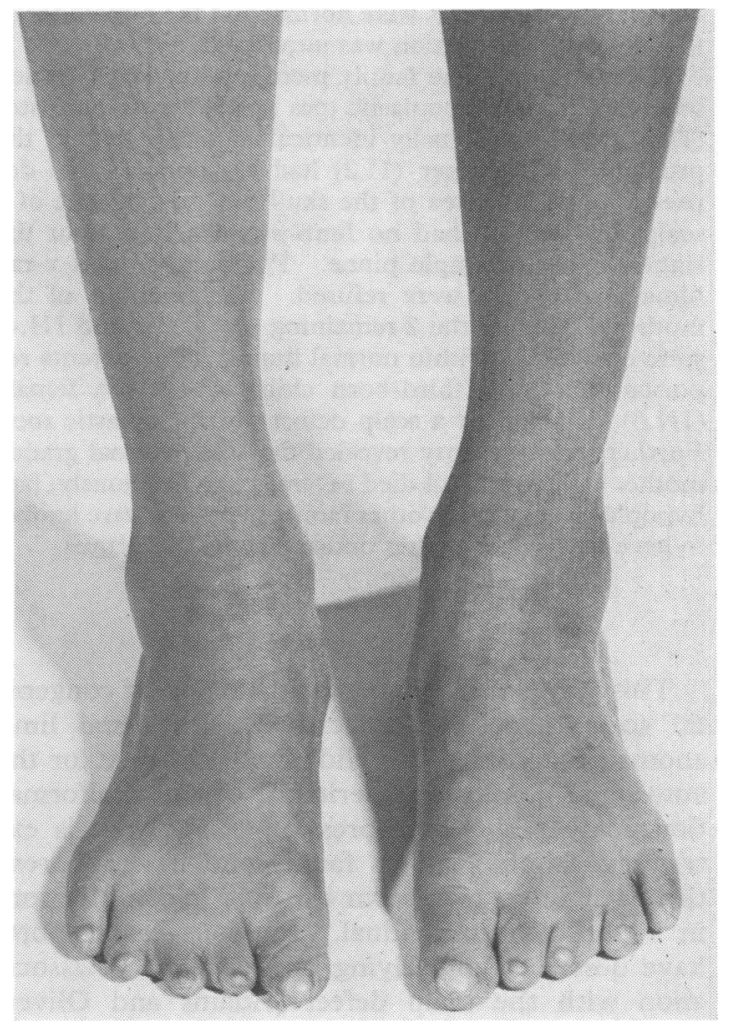

Fig. 4. Photograph of proband's sister's feet. Hypoplasia of the toes is even more pronounced than in the proband.
FIg. 3. (A) Photograph of proband's feet showing hypoplasia of the toes.
(B) $X$-ray of proband's feet revealing absence of most of the distal phalanges. 
The hands and fingers were normal and the remainder of the physical examination was unremarkable.

Examination of the family members showed a healed scalp defect and hypoplastic toes in the 9-year-old sister (III.2) (Fig. 4) virtually identical to those seen in the proband. The father (II.2) had a palpable $3 \mathrm{~cm}$ depression at the vertex of the skull but no evidence of a scalp defect. He had no limb abnormalities, but the right ear had a simple pinna. Photographs and $x$-ray films of the skull were refused. Examinations of the mother (II.1) and the 2 remaining sibs (III.1 and III.4) were completely within normal limits. The parents reported that their third-born child, a stillborn female (III.3), had neither a scalp defect nor hypoplastic toes. Further family history revealed that the paternal grandmother (I.1), who had died several years previously, had hypoplastic toes. No other family members were known to have these or any other unusual physical features.

\section{Discussion}

This family represents the fifth report of congenital scalp defects in association with distal limb anomalies and provides additional evidence for the autosomal dominant inheritance of this malformation complex. The expression of the trait is extremely variable in this family and it is apparent that each defect may occur alone, or in combination, in a particular individual. Previous case reports have described underlying bony defects in association with the scalp defect (Adams and Oliver, 1945; Farmer and Maxmen, 1960; Scribanu and Temtamy, 1975). Such a bony abnormality was not present in our proband; however, examination of the father was suggestive of a defect in the cranium. This could unfortunately not be confirmed radiologically. An additional feature of this malformation complex may be cutis marmorata which has been reported previously (Kahn and Olmedo, 1950; Scribanu and Temtamy, 1975) and was present in our patient. Two of our family $\stackrel{\mathbb{D}}{\circ}$ members also had a minor ear anomaly, which may or may not be related to the other defects.

Although most reported cases of this syndrome? had minor limb malformations, limited to hypoplasia of the toes, the earliest report describes $\overline{0}$ affected individuals with severe limb malformations, 흔 including amputations of the lower extremities be- $\frac{\bar{\omega}}{\not}$ low the knees and major malformations of the hands $\mathbb{\Phi}$ (Adams and Oliver, 1945). Other individuals in the same family had minor anomalies similar to those ${ }^{\mathrm{s}}$ reported in our patients. This may be of signifi- $\overrightarrow{0}$ cance in the genetic counselling of families affected with this disorder.

We thank Dr Emmanuel Shapira for allowing us to study his patient.

\section{RBFERENCES}

Adams, F. H. and Oliver, C. P. (1945). Hereditary deformities in $\sigma$ man. Fournal of Heredity, 36, 3-7.

Beresford, O. D. and Samman, P. D. (1948). Congenital skin defect of the newborn. Archives of Disease in Childhood, 23, 190-194.

Callaway, J. L., Noojin, R. O., Riley, K. A., and Kuhn, B. H. (1946). Congenital ectodermal defect: report of an unusual case involving $(\mathrm{D}$ scalp and leg. Fournal of Pediatrics, 28, 214-216.

Cutlip, B. D., Jr., Cryan, D. M., and Vineyard, W. R. (1967). Congenital scalp defects in mother and child. American fournal of $\bar{O}$ Diseases in Children, 113, 597-599.

Farmer, A. W. and Maxmen, M. D. (1960). Congenital absence of skin. Plastic and Reconstructive Surgery, 25, 291-297.

Feud, P., Rhodes, A. W., and Weisz, A. (1945). Hereditary sk defect in the newborn infant. Fournal of Pediatrics, 27, 591-5i

Hodgman, J. E., Mathies, A. W., Jr., and Levan, N. E. (1965). Congenital scalp defects in twin sisters. American fournal $\mathrm{g}_{f}$ Diseases of Children, 110, 293-294.

Johnsonbaugh, R. E., Light, I. J., and Sutherland, J. M. (1965) Congenital scalp defects in father and son. American fournal of Diseases of Children, 110, 297-298.

Kahn, E. A. and Olmedo, L. (1950). Congenital defect of the scalp. Plastic and Reconstructive Surgery, 6, 435-439.

Scribanu, N. and Temtamy, S. A. (1975). The syndrome of aplasia cutis congenita with terminal transverse defects of limbs. Fournal of Pediatrics, 87, 79-82.

Walker, J. C., Koenig, J. A., Irwin, L., and Meijer, R. (1960). Congenital absence of skin. Plastic and Reconstructive Surgery, 26, 209-218. 